\title{
Hyperventilation test for diagnosis of left-to-right circulatory shunts
}

\author{
S. R. Reuben and J. Butler ${ }^{1}$ \\ From the Cardiac Department, Radcliffe Infirmary, Oxford
}

Pulmonary and systemic arterial carbon dioxide tensions $\left(\mathrm{PCO}_{2}\right)$ were measured at cardiac catheterization in 15 patients with left-to-right circulatory shunts and in 15 patients with valvular heart disease. The measurements were performed under resting conditions and at 5-sec intervals during a 30-sec period of hyperventilation. In both groups the systemic arterial $\mathrm{PCO}_{2}$ fell significantly during hyperventilation. In patients with left-to-right shunts the pulmonary arterial $\mathrm{PCO}_{2}$ fell significantly $(P<0 \cdot 0 \mathrm{I})$ IO sec after the onset of hyperventilation, but in the patients without shunts, hyperventilation produced no change in the pulmonary arterial $\mathrm{PCO}_{2}$.

There are now several acceptable procedures to confirm the presence of a left-to-right shunt in patients with septal defects or a persistent ductus arteriosus. The standard practice is to demonstrate a 'step-up' in the blood oxygen saturation at the site of the shunt and distal to it (Dexter et al., 1947). Additional procedures to confirm a circulatory shunt include the description of indicator dye dilution timeconcentration curves (Swan, Zapata-Diaz, and Wood, 1953). The use of a catheter-tip platinum electrode with either inhalation of hydrogen (Clark and Bargeron, 1959; Vogel, Grover, and Blount, 1962) or the injection of ascorbic acid (Kaplan et al., I96I) are based on the same principle as indicator dye dilution curves, as is the nitrous oxide test (Sanders and Morrow, 1958). More recently, Gamble and his colleagues introduced a fiberoptic catheter for intracardiac oximetry (Gamble et al., 1965).

This paper presents data on a further simple test for the detection of moderate left-to-right circulatory shunts and is based on the appearance, in the pulmonary artery, of hypocarbic blood after a short period of hyperventilation.

\section{Patients and methods}

A total of 30 patients was studied at routine cardiac catheterization. Fifteen patients had circulatory shunts with pulmonary/systemic blood flow ratios ranging from $1 \cdot 5: 1$ to $4 \cdot 7: 1$ (Table I). Nine patients had atrial septal defects, 4 had ventricular

Received 18 March 1971.

1 Present address: Department of Medicine, Division of Pulmonary Diseases, University of Washington, Seattle, U.S.A. septal defects, and 2 had persistent ductus arteriosus. The control group consisted of 15 patients undergoing investigation for valvular heart disease (Table 2).

Conventional right heart catheterization was performed from either a right antecubital vein or the right saphenous vein. In the adolescent and adult patients the right femoral artery was catheterized with a microcatheter by a modified Seldinger technique. In the infants, femoral arterial blood samples were taken by direct arterial puncture. Heparinized blood samples were removed from the right heart and femoral artery and analysed for oxygen and carbon dioxide tension using Standard Radiometer electrodes. Analysis of paired samples usually agreed within 2 per cent of each other. Pulmonary and systemic blood flows were determined by the Fick principle (Dexter et al., 1947) after a 5-minute expired air collection.

On completion of the routine measurements, blood samples were withdrawn from the pulmonary and femoral arteries and analysed for carbon dioxide tension $\left(\mathrm{PCO}_{2}\right)$. The patients were then instructed to hyperventilate for a period of 30 seconds. Further blood samples were withdrawn from both sites at 5 -second intervals over the following 25 seconds and likewise analysed for $\mathrm{PCO}_{2}$.

The patients in the control group, who had mitral or aortic valve disease, underwent retrograde catheterization of the aorta and left heart chambers, with appropriate angiocardiography where indicated.

\section{Results}

The diagnostic and blood gas data for the patients with proven shunts are shown in Table $I$ and for the control group (no shunt) in Table 2. The resting femoral arterial $\mathrm{PCO}_{2}$ 
of both groups is lower than the normal value of $40 \mathrm{mmHg}$, indicating that all the patients were hyperventilating, to some extent, under resting conditions. Hyperventilation produced femoral arterial hypocarbia in both groups of patients; all the $\mathrm{PCO}_{2}$ values were significantly reduced from the resting value $(P<0.001)$. The patients with proven left-to-right shunts showed reductions in the pulmonary arterial $\mathrm{PCO}_{2}$ from the resting value, though it was only after hyperventilating for Io seconds that the reduced values showed statistically significant differences from the initial value $(P<0.005)$. The largest and most significant fall in both femoral and pulmonary arterial $\mathrm{PCO}_{2}$ occurred 20 to 25 seconds after the start of hyperventilation $(P<0.001)$. Table 2 shows that hyperventilation produced no significant change in the pulmonary arterial $\mathrm{PCO}_{2}$ values of the control group of patients

TABLE I Systemic and pulmonary arterial $\mathrm{PCO}_{2}$ in patients with proven shunts

\begin{tabular}{|c|c|c|c|c|c|c|c|c|c|c|}
\hline \multirow[t]{2}{*}{$\begin{array}{l}\text { Case } \\
\text { No. }\end{array}$} & \multirow[t]{2}{*}{$\operatorname{Sex}$} & \multirow[t]{2}{*}{ Diagnosis } & \multirow{2}{*}{$\begin{array}{l}\text { Body } \\
\text { surface } \\
\text { area } \\
\left(m^{2}\right)\end{array}$} & \multirow{2}{*}{$\begin{array}{l}\text { Cardiac } \\
\text { index } \\
\left(l . / \min / m^{2}\right)\end{array}$} & \multirow{2}{*}{$\begin{array}{l}\text { Pulm./ } \\
\text { systemic } \\
\text { flow } \\
\text { ratio }\end{array}$} & \multicolumn{5}{|c|}{$\begin{array}{l}\text { Pulmonary artery } \\
\text { sampling period }(\mathrm{sec})\end{array}$} \\
\hline & & & & & & Rest & $5-10$ & $10-15$ & $15-20$ & $20-25$ \\
\hline $\mathbf{I}$ & \multirow{15}{*}{$\begin{array}{l}\mathbf{F} \\
\mathbf{M} \\
\mathbf{F} \\
\mathbf{F} \\
\mathbf{M} \\
\mathbf{M} \\
\mathbf{F} \\
\mathbf{F} \\
\mathbf{M} \\
\mathbf{F} \\
\mathbf{M} \\
\mathbf{F} \\
\mathbf{M} \\
\mathbf{F} \\
\mathbf{M}\end{array}$} & Atrial septal defect & $I \cdot 6$ & $2 \cdot 8$ & 4.0:1 & 29 & 28 & 27 & 23 & 22 \\
\hline 2 & & Atrial septal defect & $\mathbf{2} \cdot 0$ & $2 \cdot 6$ & $3 \cdot 6: 1$ & 37 & 33 & 28 & 24 & 22 \\
\hline 3 & & Atrial septal defect & $I \cdot 5$ & $2 \cdot 5$ & $\mathbf{2} \cdot \mathbf{I}: \mathbf{I}$ & 32 & 27 & 22 & $2 I$ & 20 \\
\hline 4 & & Ventricular septal defect & $1 \cdot 7$ & 3.5 & $I \cdot 9: I$ & 37 & 37 & 32 & 30 & 29 \\
\hline 5 & & Atrial septal defect & $1 \cdot 7$ & $2 \cdot 6$ & $3 \cdot 0: 1$ & 31 & 30 & 30 & 28 & 28 \\
\hline 6 & & Persistent ductus arteriosus & $I \cdot 8$ & $3 \cdot 4$ & $2 \cdot 3: 1$ & 34 & 33 & 29 & 28 & 23 \\
\hline 7 & & Atrial septal defect & $I \cdot 0$ & $2 \cdot 4$ & $3 \cdot 4: 1$ & 25 & 27 & 27 & 26 & 20 \\
\hline 8 & & Atrial septal defect & $I \cdot 4$ & $6 \cdot 3$ & $4 \cdot 7: 1$ & 28 & 27 & 25 & 23 & 27 \\
\hline 9 & & Ventricular septal defect & $\mathbf{I} \cdot \mathbf{7}$ & $2 \cdot 4$ & $2 \cdot 0: 1$ & 36 & 35 & 32 & 29 & 24 \\
\hline $10 *$ & & Persistent ductus arteriosus & $I \cdot 5$ & $2 \cdot 1$ & $I \cdot 6: I$ & 34 & 31 & 26 & 25 & \\
\hline II * & & Ventricular septal defect & 0.7 & $3 \cdot 0$ & $I \cdot 5: I$ & 33 & 24 & 22 & & \\
\hline $12 \star$ & & Atrial septal defect & 0.9 & 4.5 & $3 \cdot 4: 1$ & 36 & 27 & & & \\
\hline $13^{*}$ & & Ventricular septal defect & $1 \cdot 8$ & $2 \cdot 6$ & $2 \cdot 0: 1$ & 48 & 42 & 40 & & \\
\hline $14^{*}$ & & Atrial septal defect & $I \cdot 6$ & $1 \cdot 4$ & $2 \cdot 4: I$ & 31 & 20 & 16 & & \\
\hline $15^{\star}$ & & Atrial septal defect & $1 \cdot 5$ & 3.4 & $2 \cdot 9: 1$ & 42 & 34 & & & \\
\hline Mean & & & & & & $34 \cdot 2$ & $30 \cdot 3$ & $27 \cdot 4$ & $25 \cdot 7$ & $23 \cdot 9$ \\
\hline $\mathrm{SD}$ & & & & & & $5 \cdot 7$ & 5.5 & $5 \cdot 8$ & 3.0 & $3 \cdot 4$ \\
\hline $\mathbf{t}$ & & & & & & & $1 \cdot 89$ & $3 \cdot 13$ & $4 \cdot 34$ & $4 \cdot 93$ \\
\hline
\end{tabular}

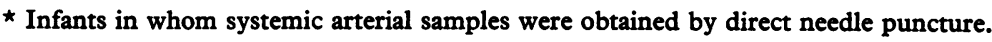

TABLE 2 Systemic and pulmonary arterial $\mathrm{PCO}_{2}$ in patients without shunts

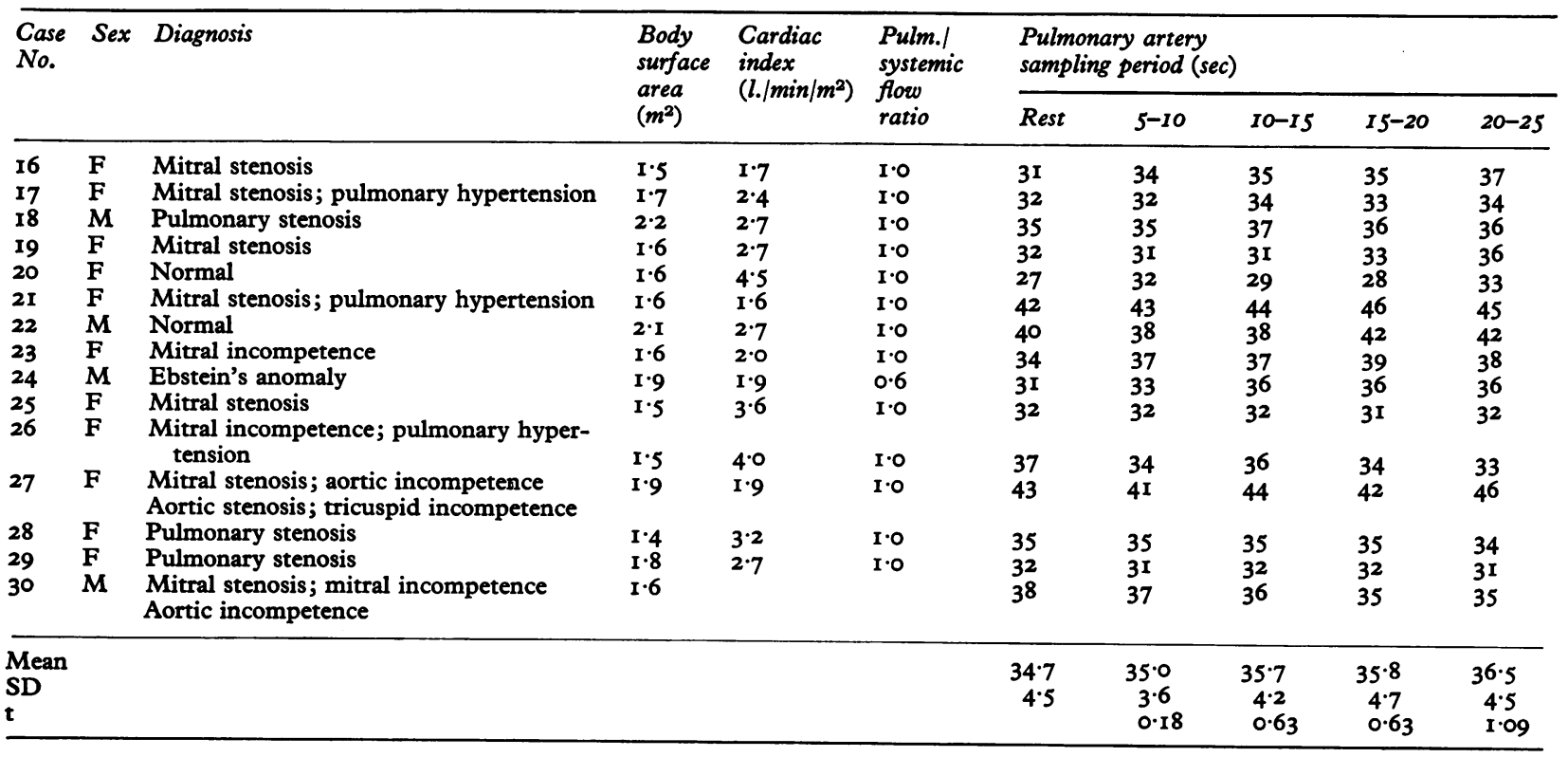


$(\mathbf{P}<0.30)$. The Fig. shows in graphical form the changes that occurred in femoral and pulmonary arterial $\mathrm{PCO}_{2}$ during hyperventilation for both groups of patients.

\section{Discussion}

The majority of procedures for the diagnosis of circulatory left-to-right shunts depend on the early appearance, in the right heart chambers or vessels distal to the shunt, of

\begin{tabular}{lllll}
\hline $\begin{array}{l}l \\
\text { Systemic artery } \\
\text { sampling period (sec) }\end{array}$ & & & \\
\hline Rest & $5-10$ & $10-15$ & $15-20$ & $20-25$ \\
\hline 25 & 26 & 23 & 18 & 17 \\
33 & 30 & 22 & 19 & 18 \\
30 & 20 & 17 & 15 & 14 \\
23 & 23 & 17 & 16 & 16 \\
31 & 33 & 28 & 24 & 23 \\
34 & 25 & 25 & 25 & 24 \\
27 & 27 & 23 & 19 & 17 \\
31 & 31 & 21 & 16 & 15 \\
35 & 23 & 18 & 18 & 17 \\
23 & & & & \\
& & & & \\
44 & 35 & & & \\
34 & 22 & & & \\
41 & 30 & & & \\
\hline $32 \cdot 5$ & $27 \cdot 1$ & $21 \cdot 6$ & $18 \cdot 9$ & $17 \cdot 9$ \\
$5 \cdot 8$ & $4 \cdot 7$ & $3 \cdot 8$ & $3 \cdot 5$ & 3.4 \\
& $2 \cdot 52$ & 4.94 & $6 \cdot 25$ & $6 \cdot 73$ \\
\hline
\end{tabular}

Systemic artery

sampling period (sec)

\begin{tabular}{lllll}
\hline Rest & 5-10 & $10-15$ & $15-20$ & $20-25$
\end{tabular}

\begin{tabular}{lllll}
\hline 32 & & & & \\
30 & 27 & 23 & 21 & 19 \\
35 & 20 & 16 & 15 & 14 \\
28 & 19 & 15 & 13 & 13 \\
22 & 23 & 23 & 21 & 21 \\
37 & 34 & 29 & 26 & 25 \\
41 & 26 & 21 & 21 & 19 \\
33 & 31 & 28 & 27 & 26 \\
33 & 27 & 25 & 24 & 24 \\
30 & 30 & 25 & 24 & 23 \\
30 & 30 & 28 & 25 & 24 \\
35 & 34 & 33 & 23 & 22 \\
27 & 25 & 22 & 22 & 21 \\
26 & 23 & 21 & 20 & 20
\end{tabular}

\begin{tabular}{rcccc}
\hline $31 \cdot 3$ & $26 \cdot 9$ & $23 \cdot 8$ & $21 \cdot 7$ & $20 \cdot 6$ \\
$5 \cdot 1$ & $4 \cdot 9$ & $5 \cdot 1$ & $4 \cdot 0$ & $4 \cdot 0$ \\
& $2 \cdot 29$ & 3.79 & $5 \cdot 35$ & $6 \cdot 39$ \\
\hline
\end{tabular}

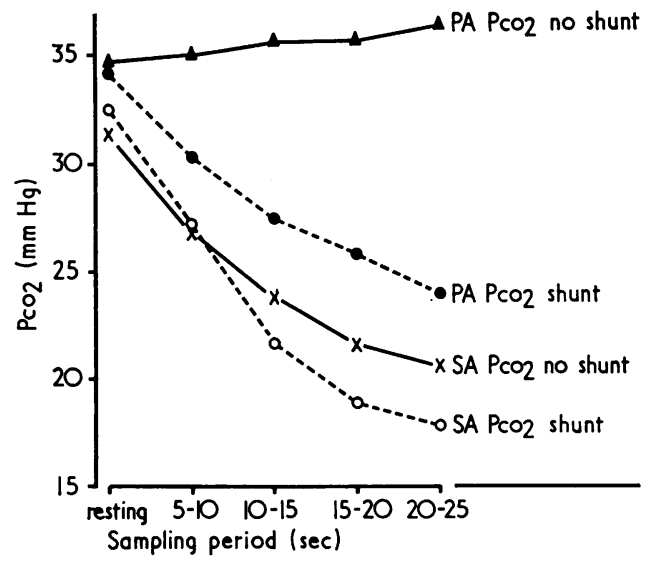

FIG. I Pulmonary arterial $\left(\mathrm{PA} \mathrm{PCO}_{2}\right)$ and systemic arterial $\left(\mathrm{SA} \mathrm{PCO}_{2}\right)$ carbon dioxide tensions during hyperventilation in patients with left-to-right shunts (--O-- and -- - --) and no shunts ( $-\Delta-$ and $-\times-)$. The data points represent the average values for the group at each sampling point.

either a physiological substance in higher concentration than normal, or a foreign material that has been introduced into the circulation by injection or inhalation. The standard procedure for confirming a left-toright shunt of blood is to demonstrate an increase in the oxygen saturation of blood at and distal to the point of entry of the suspected shunt. This is simply the result of mixing of venous blood with low oxygen saturation with shunted fully-saturated blood from the left heart chambers or aorta (Dexter et al., 1947).

The indicator dye dilution method is an example of the use of the early appearance of a foreign material to confirm the presence of either left-to-right or right-to-left circulatory shunts. Characteristic distortions of the normal time-concentration curve are produced (Swan et al., 1953). The use of a catheter-tip platinum electrode with either inhalation of hydrogen (Clark and Bargeron, 1959; Vogel et al., 1962) or the injection of ascorbic acid (Kaplan et al., 196I) is based on the same principle as indicator dye dilution curves, as is the $\mathrm{N}_{2} \mathrm{O}$ test (Sanders and Morrow, 1958). Catheterization of the right heart chambers with a fiberoptic catheter allows instantaneous measurement of blood oxygen saturation and this provides a sophisticated procedure for the detection of small circulatory shunts (Gamble et al., 1965).

Reversal of a small left-to-right shunt at atrial level can be shown by performing 
Valsalva's manoeuvre while monitoring systemic arterial blood oxygen saturation with an earpiece oximeter (Lee and Gimlette, I957; McIlroy, 1959). After release of the strain there is a large inflow to the right atrium sufficient to reverse the shunt and produce a transient reduction in oxygen saturation.

The principle underlying the procedure described here is similar to those already described. Hyperventilation produces a decrease in alveolar carbon dioxide tension, which leads to a fall in the $\mathrm{PCO}_{2}$ of the pulmonary venous and left heart blood (Comroe et al., 1962). In the presence of a left-to-right shunt, the hypocarbic left heart blood will be shunted into the right heart chambers, lowering the $\mathrm{PCO}_{2}$ of blood distal to the defect. It is unlikely that hyperventilation lowers the mixed venous blood $\mathrm{PCO}_{2}$ by perfusion of the tissues with hypocarbic systemic arterial blood, because the venous sump for carbon dioxide is so great. Moreover, the muscular work involved in hyperventilation might be expected to increase the mixed venous $\mathrm{PcO}_{2}$. Table 2 does in fact show that there was no fall in pulmonary arterial $\mathrm{PCO}_{2}$ during hyperventilation in the control group of patients.

This procedure is simple to perform and requires only a standard blood gas analyser. It could be utilized as a screening test for leftto-right shunts without the need for formal catheterization, since the use of pulmonary artery 'float' catheters has become popular (Thomas, Malmcrona, and Shillingford, 1965). Reliable information could be obtained from analysis of a resting pulmonary artery blood sample and one withdrawn IO-I5 seconds after the start of hyperventilation.

\section{References}

Clark, L. C., Jr., and Bargeron, L. M., Jr. (1959) Left-to-right shunt detection by an intravascular electrode with hydrogen as an indicator. Science, 130, 709.

Comroe, J. H., Jr., Forster, R. E., II, DuBois, A. B., Briscoe, W. A., and Carlsen, E. (1962). The Lung, 2nd ed. Year Book Medical Publishers, Chicago.

Dexter, L., Haynes, F. W., Burwell, C. S., Eppinger, E. C., Sosman, M. C., and Evans, J. M. (1947). Studies of congenital heart disease. III. Venous catheterization as a diagnostic aid in patent ductus arteriosus, tetralogy of Fallot, ventricular septal defect and atrial septal defect. fournal of Clinical Investigation, 26, 56I.

Gamble, W. J., Hugenholtz, P. G., Monroe, R. G., Polanyi, M., and Nadas, A. S. (1965). The use of fiberoptics in clinical cardiac catheterization. I. Intracardiac oximetry. Circulation, 31, 328.

Kaplan, S., Clark, L. C., Edwards, F. K., Gallaher, M. E., and Fox, R. P. (196I). Localization of right to left shunts with an intravascular polarographic anode sensitive to ascorbic acid. American fournal of Cardiology, 8, 659 .

Lee, G. de J., and Gimlette, T. M. D. (1957). A simple test for interatrial communication. British Medical fournal, r, 1278.

McIlroy, M. B. (1959). The clinical uses of oximetry. British Heart fournal, $21,293$.

Sanders, R. J., and Morrow, A. G. (1958). The diagnosis of circulatory shunts by the nitrous oxide test; improvements in technic and methods for quantification of the shunt. Circulation, 18, 856.

Swan, H. J. C., Zapata-Diaz, J., and Wood, E. H. (1953). Dye dilution curves in cyanotic congenital heart disease. Circulation, 8, 70.

Thomas, M., Malmcrona, R., and Shillingford, J. (1965). Hemodynamic changes in patients with acute myocardial infarction. Circulation, 3I, $81 \mathrm{I}$.

Vogel, J. H. K., Grover, R. F., and Blount, S. G., Jr. (I962). Detection of the small intracardiac shunt with the hydrogen electrode. A highly sensitive and simple technique. American Heart fournal, 64, 13.

Requests for reprints to Dr. S. R. Reuben, Cardiac Department, Radcliffe Infirmary, Oxford. 